\title{
As representações de exu em $A$ morte e a morte de Quincas Berro Dágua, de Jorge Amado
}

Fernando Reis de Sena ${ }^{1}$

http://lattes.cnpq.br/4907006999922172

Jares Gomes Lima ${ }^{2}$

http://lattes.cnpq.br/1702450590102185

Recebido em: 19/09/2018

Aceito em: 13/01/2019

Resumo: Neste artigo, discute-se a presença de Exu na construção da novela $A$ morte e a morte de Quincas Berro Dágua, de Jorge Amado. São apresentadas teorias que versam sobre as tradições afrobrasileiras, no sentido de sustentar as discussões entre literatura e religiosidade, visto que o texto amadiano faz referências aos mitos iorubás e ao candomblé. Assim, o artigo traz, por um lado, o debate acerca do fazer literário, e por outro, as tradições religiosas.

Palavras-chave: Candomblé. Literatura e religiosidade. Orixás.

Abstract: In this article, we discuss the presence of Exu in the construction of the novel A morte e a morte de Quincas Berro Dágua, by Jorge Amado. Theories about Afro-Brazilian traditions are presented in order to support discussions between literature and religiosity, since the Amadian text makes references to Yoruba myths and Candomble myths. Thus, the article brings, on the one hand, the debate about the literary work of, and on the other, the religious traditions.

Keywords: Candomblé. Literature and religiosity. Orixás.

\section{Considerações iniciais}

A literatura produzida a partir da Semana de Arte Moderna (1922) inaugurou um novo modo de contar história, mesclando técnicas, gêneros e linguagens. Os fatos político-sociais passaram a refletir na ficção, contribuindo para o fortalecimento ideológico da produção literária nas décadas seguintes. A queda da Bolsa de valores de Nova Iorque, a instauração do Estado Novo, a crise da cafeicultura, a Segunda Guerra Mundial, o combate ao socialismo, a política nazista de Hitler, a decadência da burguesia e o êxodo rural - foram fatos que ajudaram a consolidar uma ficção mais próxima do povo e sobre o povo, denunciando e problematizando as migrações internas, a hostilização do homem pela cidade, pela natureza, pelo próprio homem e pela globalização. Entre os escritores desta época está Jorge Leal Amado de Faria.

Jorge Amado nasceu em 1912, em Ferradas, distrito de Itabuna, na Bahia. Ainda criança mudou para a cidade de Ilhéus onde cursou os primeiros anos de estudo. Após mudar para Salvador, começou a trabalhar em um jornal local, dando início a carreira de escritor. Amado possui uma ampla produção literária traduzida em diversos idiomas e costuma ser

\footnotetext{
1 Mestre em Letras: Linguagens e Representações pela Universidade Estadual de Santa Cruz. E-mail: ffrsena@gmail.com

2 Doutorando e Mestre em Estudos Linguísticos pela Universidade Federal do Espirito Santo. E-mail: jares 16@hotmail.com
} 
dividida em duas fases: a panfletária e a de costumes. A primeira, formada pelas obras O país do Carnaval (1931); Cacau (1993); Suor (1934); Jubiabá (1935); Mar Morto (1936); Capitães da areia (1937); Terras do sem-fim (1942); São Jorge dos Ilhéus (1944); Seara Vermelha (1946) e Os subterrâneos da liberdade (1952) - é caracterizada pelas ideias socialistas e nos problemas do sul da Bahia, principalmente os relacionados ao desenvolvimento econômico da região cacaueira, cujos enredos destacam a opressão do trabalhador rural e as precárias condições de sobrevivência das classes populares.

Na segunda fase, o foco é no costume do povo baiano, nas comidas típicas, na religiosidade, na música, na capoeira e no folclore. Temas como a sensualidade feminina e a prostituição foram utilizadas para criticar a sociedade tradicional sustentada pela igreja e pela família. Os protagonistas são sujeitos marginalizados que rompem as condutas sociais e estão engajados numa causa coletiva. São destaques desta fase Gabriela Cravo e canela (1958); A morte e a morte de Quincas Berro Dágua (1959); Dona flor e seus dois maridos (1967); Tenda dos milagres (1970); Teresa Batista cansada de guerra (1973) e Tieta do agreste (1977).

Este estudo, de cunho descritivo-bibliográfico, analisa o texto de $A$ morte e a morte de Quincas Berro Dágua, publicado primeiramente em 1959, na Revista Senhor e editado em livro em 1961. O enredo se concentra nas mortes de Joaquim Soares da Cunha - respeitado funcionário público, bom esposo e pai dedicado - que decidiu abandonar a família para se tornar Quincas Berro Dágua - um vagabundo e imoral, tendo sua existência negada pela família, a qual passou a vê-lo como desgosto e humilhação. Após a morte de Quincas, sua família acreditava na possibilidade de reconstruir a imagem do venerado Joaquim. Contudo, durante o velório, o corpo de Berro Dágua é levado pelos companheiros de cachaça numa embarcação à Baía de Todos os Santos, onde Quincas mergulha nas águas míticas da Bahia, cumprindo seu desejo de ter como última morada o mar de Iemanjá.

Diante disso, esta pesquisa relaciona ficção e religiosidade, atentando-se às tradições orais, às mitologias iorubás e aos segredos dos cultos afro-brasileiros; e está organizada em duas seções: a primeira - dedicada a reflexão sobre os orixás, principalmente Exu; a segunda - discute a influência dos deuses africanos na composição da personalidade de Quincas Berro Dágua.

\section{Exu: um mensageiro}

Reginaldo Prandi, em Mitologia dos orixás (2001), afirma que os orixás são deuses que receberam do Ser Supremo, Olorum, a responsabilidade de criar e governar o mundo. Para cada um, foi atribuído um poder a ser exercido sobre a vida em sociedade e a personalidade humana. Seu culto está difundido em todas as regiões do Brasil, com nomes e atributos diversos, mas é com o candomblé que o reconhecimento à religiosidade afro-brasileira se destacou. Nessa tradição, Prandi, no texto "Deuses africanos no Brasil" (1997, online), explica que "cada pessoa pertence a um deus determinado, que é o senhor de sua cabeça e mente e de quem herda características físicas e de personalidade”. Segundo a tradição, todos descendem de um determinado orixá e dele se adquire características boas ou ruins. Sobre isso, o sociólogo pontua:

A cada um destes cabe o papel de reger e controlar forças da natureza e aspectos do mundo, da sociedade e da pessoa humana. Cada um tem suas próprias características, elementos naturais, cores simbólicas, vestuário, músicas, alimentos, bebidas, além de se caracterizar por ênfase em certos traços de personalidade, desejos, defeitos, etc. Nenhum orixá é nem inteiramente bom, nem inteiramente mau. Noções ocidentais de bem e mal estão ausentes da religião dos

https://periodicos.unifap.br/index.php/letras Macapá, v. 8, n. 3, $2^{\circ}$ sem., 2018 
Os orixás estão ligados e regem aspectos da natureza, como os rios, o mar, o trovão e o metal. Entre eles, Exu é um dos mais conhecidos e polemizados. Em $A$ busca da Africa no candomblé: tradição e poder no Brasil (2009), Stefania Capone defende que Exu é a figura mais complexa e humana entre as divindades afro-brasileiras. Para a antropóloga:

[...] é o grande comunicador, o intermediário entre os deuses e os homens, o restaurador da ordem do mundo, mas, ao mesmo tempo, como senhor do acaso no destino dos homens, desfaz as abordagens conformistas do universo, ao introduzir a desordem e a possibilidade de mudança (CAPONE, 2009, p. 54).

Nota-se, portanto, que Exu é uma figura dúbia e, talvez, por estas características arroladas por Capone que sua personalidade se aproxima da humana. A irreverência, a esperteza e a irascibilidade juntamente com a força mágica que exerce sobre o homem e a representação simbólica das efígies de falo desproporcional associa Exu ao pecado carnal e ao diabo cristão, especificamente o Èsùs- Elégbéra dos iorubás, responsabilizado pelas as forças malignas, a fonte de todos os males, autor da instabilidade, do caos, da confusão, da guerra e das calamidades públicas. Exu é, nesse sentido, considerado o "responsável pelos sonhos eróticos, pelo adultério e por toda relação sexual ilícita” (CAPONE, 2009, p. 59).

Apesar dessas atribuições negativas, Exu tem função indispensável nos cultos afrobrasileiros, pois sem sua presença não há comunicação entre o Orun (céu) e o Aiyê (Terra). Para Prandi (2001, p. 20-21), Exu:

Está sempre presente, pois o culto de cada um dos demais orixás depende de seu papel de mensageiro. Sem ele orixás e humanos não podem se comunicar. Também chamado de Legbá, Bará e Eleguá, sem sua participação não existe movimento, mudança ou reprodução, nem trocas mercantis, nem fecundação biológica.

Alguns teóricos consideram Exu um orixá, enquanto outros o classificam apenas como mensageiro e intermediário. Em $O$ duplo e a metamorfose: a identidade em comunidade nagô (2008, p. 91), Monique Augras defende que "Exu não é orixá, mas sim a personificação do princípio da transformação". Exu não expressa maldade, pois suas ações são resultantes de sua pluralidade, polivalência, multiplicidade e imutabilidade. O Exu dos terreiros nagô tampouco lembra a encarnação do mal, é perigoso, mas é por ser muito poderoso. Deve ser conhecido e tratado como convém. Vem em primeiro em tudo: primeira oferenda, primeiro dia da semana, primeira cantiga - o primogênito do mundo (AUGRAS, 2008). Primeiramente, as oferendas são feitas para Exu, a fim de levar as indagações e trazer as respostas, cumprindo a sua missão de mensageiro. Porém, só lhe é oferecido porque se pensa nas cerimônias seguintes, há o medo de que possa atrapalhar, atribuindo a ele a qualidade de empecilho e estorvo (PRANDI, 2001).

Foi sem dúvida o processo de cristianização de Oxalá e outros orixás que empurrou Exu para o domínio do inferno católico, como um contraponto requerido pelo molde sincrético. Pois, ao se ajustar a religião dos orixás ao modelo da religião cristã, faltava evidentemente preencher o lado satânico do esquema deus-diabo, bem mal, salvação-perdição, céu-inferno, e quem melhor que Exu para o papel do demônio? (PRANDI, 2001, p. 51). 
Devido ao molde sincrético, citado pelo sociólogo, outras religiões que se desenvolveram a partir do culto aos orixás trouxeram para Exu as características negativas presentes no desmembramento entre o bem e o mal. Apesar disso, tem muitas funções, sendo considerado como uma divindade múltipla, assim como outros "que são reconhecidos e venerados através de diferentes invocações, qualidades ou avatares, cada qual referido a um aspecto mítico do orixá, a sua função específica no patronato do mundo, a um acidente geográfico a que é associado etc." (PRANDI, 2001, p. 54). Prandi defende que cada ser humano tem seu próprio Exu, logo são muitas as invocações e nomes "que indicam sucintamente as distintas funções de Exu: o mensageiro, o transportador, o transformador, o repositor e o doador (PRANDI, 2001, p. 55).

Como a literatura tem o poder de expressar os entraves da vida cotidiana por meio de símbolos que se tornam significativos, percebe-se na ficção amadiana certas invocações a Exu. O texto escrito, mesmo sendo ficção, utiliza, neste caso, a realidade para se realizar. Fabio Lucas, em $O$ caráter social da ficção no Brasil (1985), explica que essa perspectiva social da literatura será sempre vista toda vez que o destino das personagens estiver ligado ao da sociedade. Com isso, a sociedade sempre se tornará alvo para as possíveis discussões ocorridas a partir do texto literário, como é o caso explorado nesta pesquisa sobre a representação de Exu na composição do enredo de $A$ morte e a morte de Quincas Berro Dágua.

\section{Quincas Berro Dágua: o filho de Exu}

Jorge Amado apesar de se dizer materialista, possuía o posto de obá de Xangô, no terreiro Axé Opô Afonjá, uma posição de honraria dentro do povo de santo, que o ajudou a construir enredos que nos aproxima das tradições afro-brasileiras. Na narrativa de $A$ morte e a morte de Quincas Berro Dágua, encontra-se referências ao candomblé e aos mitos iorubás, como esclarece Gildeci de Oliveira Leite (A TARDE TV, 2012) ao afirmar que Quincas Berro Dágua é mais um filho de Exu criado pelo escritor, assim com Pedro Archanjo, de Tenda dos Milagres, e Vadinho, de Dona-flor e Seus dois Maridos, também deste autor ${ }^{3}$. Na tradição do candomblé:

Os devotos acreditam que os homens e mulheres herdam muitos dos atributos de personalidade de seus orixás, de modo que em muitas situações a conduta de alguém pode ser espelhada em passagens míticas que relatam as aventuras dos orixás (PRANDI, 2014).

Assim, as atitudes e os comportamentos de cada pessoa são definidos de acordo com o resultado da combinação do Ori, primeiro orixá (dono da cabeça), e pelo orixá de proteção, "que atua como uma divindade associada (juntó) que complementa o primeiro" (PRANDI, 2014). Ou seja, os humanos "são apenas cópias esmaecidas dos orixás dos quais descendem” (PRANDI, 2001, p. 24). Mário Cesar Barcellos, em Os orixás e a personalidade bumana (2010), explica que, através dos cultos afro-brasileiros, é possível encontrar as respostas necessárias para entender a psique humana.

A natureza representada na figura dos orixás é capaz de exercer sobre o ser humano forças que moldam e especificam comportamentos e personalidades. As divindades que regem cada pessoa compõem um perfil comportamental denominado como eledá, uma

\footnotetext{
${ }^{3}$ Os vídeos do Seminário Chame Gente, evento realizado pela A Tarde TV para discutir o carnaval na obra de Jorge Amado e homenageá-lo, em 2012, quando o autor foi tema do carnaval da capital baiana, estão disponíveis em: < https://www.youtube.com/watch?v=dpvickcLknE>. Acesso em 13 jul. 2018.
} 
espécie de linhagem de orixás, cuja ascendência corresponde: 50\% do Ori; $25 \%$, $15 \%$ e $7 \%$ do segundo, terceiro e quarto orixá, respectivamente, além de $3 \%$ do orixá de carrego, esses números podem variar de pessoa para pessoa (BARCELLOS, 2010).

Barcellos e Prandi divergem no que concerne a definição da quantidade de orixás na formação do perfil do sujeito. Enquanto Prandi considera a presença de dois deuses, Barcellos acredita no mínimo em cinco orixás. No entanto, ambos defendem que o eledá pode ser dividido entre o bem e o mal, sendo determinado pelos interesses do adepto ou praticante.

A diferença entre o bem e o mal depende basicamente da relação entre o seguidor e seu deus pessoal, o orixá. Não há um sistema de moralidade referido ao bem-estar da coletividade humana, pautando-se o que é certo ou errado na relação entre cada indivíduo e seu orixá particular (PRANDI, 2014).

Desse modo, verifica-se que o Ori de Quincas Berro Dágua é formado pelas estripulias e as desordens representadas por Exu. Suas ações são definidas com a intenção de mudar as coisas a seu favor. Segundo Prandi (1997, online):

[...] as pessoas consagradas a Exu são inteligentes, sexy, rápidas, carnais, licenciosas, quentes, eróticas e sujas. Filhos de Exu gostam de comer e beber em demasia. Não se deve confiar nunca num filho ou numa filha de Exu. Eles são os melhores, mas eles decidem quando o querem ser. Não são dados ao casamento, gostam de andar sozinhos pelas ruas, bebendo e observando os outros para apanhá-los desprevenidos.

Quincas é beberrão, gosta de andar pelas ruas e ladeiras de Salvador, apronta com todos e é infiel não com os amigos, mas às mulheres, e representar a instabilidade e a mudança. Ele não mediu esforços para se livrar da condição de prisioneiro e refém da esposa, Otacília, e da filha, Vanda, quando vivia como Joaquim Soares da Cunha. Sua decisão foi de sair do seio familiar e passar a viver como líder dos malandros de Salvador, tendo a sua existência desprezada e negada.

Quincas Berro Dágua, ao morrer, voltara a ser aquele antigo e respeitável Joaquim Soares da Cunha, de boa família, exemplar funcionário da Mesa de Rendas Estadual, de passo medido, barba escanhoado, paletó negro de alpaca, pasta sob o braço, ouvido com respeito pelos vizinhos, opinando sobre o tempo e a política, jamais visto num botequim, de cachaça caseira e comedida (AMADO, 2005, p. 06).

A morte representa a recuperação e a recriação da memória do morto. Para a família, Joaquim, ao sair de casa, passou a agir fora do comportamento de um sujeito detentor de respeito e admiração, que poderia servir de exemplo às crianças. $\mathrm{O}$ abandono repentino fez com que todos acreditassem em uma possível possessão de forças que o atraíam para a sarjeta ou como se desenvolvesse algum distúrbio mental:

Como pode um homem, aos cinquenta anos, abandonar a família, a casa, os hábitos de toda uma vida, os conhecidos antigos, para vagabundear pelas ruas, beber nos botequins baratos, frequentar o meretrício, viver sujo e barbado, morar em infame pocilga, dormir em um catre miserável? Vanda não encontrava explicação válida. Muitas vezes, à noite, após a morte de Otacília - nem naquela ocasião solene Quincas aceitara voltar para a companhia dos seus discutira o assunto com o marido. Loucura não era, pelo menos loucura de hospício, os médicos

https://periodicos.unifap.br/index.php/letras Macapá, v. 8, n. 3, $2^{\circ}$ sem., 2018 
tinham sido unânimes. Como explicar, então? (AMADO, 2005, p. 14).

Ao transformar-se em Quincas, Joaquim almejava os mesmos caminhos do seu Ori: as ruas e a liberdade. Berro Dágua queria a mudança, o novo, e, para isso, foi capaz de tudo, inclusive desestabilizar a família, exercendo as potencialidades dos que descendem de Exu de desequilibrar, de provocar o caos sobre aqueles que ousaram desafiá-lo e enganá-lo.

Por outro lado, os regidos por Exu amam com veemência, são capazes de qualquer sacrifício ou superar obstáculos para ficar com o parceiro, são fiéis aos seus princípios, causas e amigos (BARCELLOS, 2010). A relação entre Quincas e sua família não se enquadra em tal descrição. Primeiro (sentido religioso) porque os filhos de Exu não são dados ao casamento, mas gostam de viver ardentemente suas paixões e fazem de tudo para intensificá-las. E, segundo (sentido social), a família não o respeitava, tinha-o como troféu e, mesmo após sua morte, o desejo era de rememorar o velho Joaquim esquecendo a vergonha e a humilhação passada por conta das aventuras de Berro Dágua.

As pessoas que têm Exu como regente são excelentes amantes e possuem uma virilidade que impressiona e se relacionam com mais de uma pessoa, tornando-se um parceiro mais fantasioso e entusiasta no sexo (BARCELLOS, 2010). Essas atribuições não são explícitas na narrativa, mas deixa subentendido o quanto a capacidade de amar e de ser amado por Quincas está representada ao longo do enredo literário. As notícias que circularam sobre sua morte revelam a condição de amante e de conquistador.

Também naquelas casas pobres das mulheres mais baratas, onde vagabundos e malandros, pequenos contrabandistas e marinheiros desembarcados encontravam um lar, família e o amor nas horas perdidas da noite, após o mercado triste do sexo, quando as fatigadas mulheres ansiavam por um pouco de ternura, a notícia da morte de Quincas Berro Dágua foi a desolação e fez correr as lágrimas mais tristes. As mulheres choravam como se houvessem perdido parente próximo e sentiam-se de súbito desamparadas em sua miséria. Algumas somaram suas economias e resolveram comprar as mais belas flores da Bahia para o morto. Quanto a Quitéria do Olho Arregalado, cercada pela lacrimosa dedicação das companheiras de casa, seus gritos cruzavam a ladeira de São Miguel, morriam no largo do Pelourinho, eram de cortar o coração. Só encontrou consolo na bebida, exaltando, entre goles e soluços, a memória daquele inesquecível amante, o mais terno e louco, o mais alegre e sábio (AMADO, 2005, p. 46).

Quincas é amante incomparável, inteligente, alegre, amigo e companheiro. Sua a morte representou "um suspiro de alívio que se elevou uníssono dos peitos dos esposos" (AMADO, 2005, p. 07). Não há vaidade em suas conquistas, mas não pode ser considerado um simples galanteador. Pelo contrário, é um amante que desperta o desejo de todas as mulheres com quem se relaciona, além das mesmas lhe atribuírem inúmeros elogios tanto na sedução, quanto na cama. Quincas também gosta de zombar de tudo e de todos, inclusive da morte. Segundo Barcellos (2010), os filhos de Exu são gozadores, brincalhões, galhofeiros, debochados, enganadores e de sorriso aberto. Essas, talvez, sejam as características mais evidentes de Berro Dágua, percebidas especialmente na descoberta de sua morte, "uma farsa montada por ele com o intuito de mais uma vez atazanar a vida dos parentes, desgostar-lhes a existência, mergulhando-os na vergonha e nas murmurações da rua" (AMADO, 2005, p. 03).

Quincas, mesmo morto, ria de todos, com a cara de debochado: "era um morto pouco apresentável, cadáver de vagabundo falecido ao azar, sem decência na morte, sem respeito, rindo-se cinicamente, rindo-se dela, com certeza de Leonardo, do resto da família" 
(AMADO, 2005, p. 14). E, durante o velório:

Ampliou-se o sorriso canalha de Quincas ao enxergar o vulto monumental da irmã. Vanda quis tapar os ouvidos, sabia, por experiência anterior, com que palavras ele amava definir Marocas, mas que adiantam mãos sobre as orelhas para conter voz de morto? Ouviu:

- Saco de peidos!

Marocas, mais descansada da subida, sem olhar sequer o cadáver, escancarou a janela:

- Botaram perfume nele? Está um cheiro de tontear.

Pela janela aberta, o ruído da rua entrou, múltiplo e alegre, a brisa do mar apagou as velas e veio beijar a face de Quincas, a claridade estendeu-se sobre ele, azul e festiva. Vitorioso sorriso nos lábios, Quincas ajeitou-se melhor no caixão (AMADO, 2005, p. 38-39).

Todas essas características percebidas em Joaquim Soares da Cunha afloraram após a morte social. Porém, ele já havia declarado o desejo de cumprir o destino de marinheiro e ter a sua última morada nas águas. Tia Marocas afirmou que Joaquim, desde criança, apresentava comportamento fora do convencional, queria fugir com o circo, provocando um alvoroço entre os familiares, isso não evidencia o comportamento de Joaquim Soares da Cunha (antes da morte social) como também regido por Exu, mas nos revela um comportamento diferenciado dos outros sujeitos, o que viria a se tornar peça fundamental na compreensão do eledá de Quincas Berro Dágua, visível apenas após a mudança de personalidade. Ainda que a história do protagonista se assemelhe às atribuições dos filhos de Exu, descritas por Reginaldo Prandi e Mario Cesar Barcellos, Jorge Amado materializa na sua narrativa os mitos iorubás, os quais espelham no comportamento e na personalidade de Berro Dágua.

Há alguns mitos e teorias que atribuem a Exu o papel de intermediário, mensageiro e responsável pela ligação entre o divino e o profano. Nos mitos descritos por Reginaldo Prandi (2011): "Exu ganha o poder sobre as encruzilhadas", "Exu respeita o tabu e é feito o decanto dos orixás" e "Exu ajuda Olofim na criação do mundo", todas as conquistas dos orixás são resultados da confiança, do respeito e da responsabilidade que ele desperta com quem se relaciona, por esse motivo, a primazia em referenciá-lo nas práticas dos cultos.

No texto literário, a figura de Exu encontra-se refletida na personalidade de Quincas Berro Dágua, especialmente nas suas relações com os amigos que conquistou na ladeira do Tabuão, nos bares e casas de meretrício de Salvador. A descoberta de sua morte revelou um papel fulcral que Quincas exercia para a realização do Candomblé: o responsável pelas ervas sagradas que não poderiam faltar no culto.

[...] uma negra, vendedora de mingau, acarajé, abará e outras comilanças, tinha um importante assunto a tratar com Quincas naquela manhã. Ele havia-lhe prometido arranjar certas ervas difíceis de arranjar, imprescindíveis para as obrigações de candomblé (AMADO, 2005, p.08).

Quincas direta ou indiretamente tem a mesma função de Exu nas práticas religiosas: ligar o mundo profano ao sagrado. É de Quincas a incumbência de fazê-lo acontecer e o narrador faz questão de destacar a dificuldade de exercer essa função, o que concede ao protagonista certa supremacia sobre os outros personagens. Quincas, assim como Exu, é polivalente, múltiplo e imutável. Suas ações sobressaem à conduta humana. E como seu orixá regente é o mais humanizado, talvez a sobreposição entre eles (orixá e personagem), de um estar ora como protagonista, ora como coadjuvante, possa ser justificado de acordo com a concepção dos cultos afro-brasileiros, em que as características do orixá se juntam às do humano, resultando num sujeito com as mesmas atribuições do deus dono de sua 
cabeça.

É importante destacar que o protagonista de A Morte e a morte de Quincas Berro Dágua também exerce o papel de chefe de sua coletividade:

Os jogadores de porrinha, de ronda, de sete-e-meio suspendiam as emocionantes partidas, desinteressados dos lucros, apatetados. Não era Berro Dágua o seu indiscutido chefe? Caía sobre eles a sombra da tarde como luto fechado. Nos bares, nos botequins, no balcão das vendas e armazéns, onde quer que se bebesse cachaça, imperou a tristeza e a consumação era por conta da perda irremediável (AMADO, 2005, p. 44).

Quincas herda o caráter de mensageiro e dominador de Exu, características que podem ser vistas na sua capacidade de realizar e de mudar os sentidos (o jogo) a seu favor mesmo após a morte. Neste caso, afirma-se que Quincas não foi guiado pelos companheiros após sua morte à Baia de Todos os Santos, mas os guiou, de forma mágica e misteriosa, uma vez que foi para realizar o desejo revelado em vida e também para concretizar o seu destino que o mar lhe tinha reservado:

Curió e Pé-de-Vento saíram na frente. Quincas, satisfeito da vida, num passo de dança ia entre Negro Pastinha e cabo Martim de braço dado.

[...] Pelo jeito, aquela ia ser noite memorável, inesquecível. Quincas Berro Dágua estava num dos seus melhores dias. Um entusiasmo incomum apossara-se da turma, sentiam-se donos daquela noite fantástica, quando a lua cheia envolvia o mistério da cidade da Bahia. Na ladeira do Pelourinho casais escondiam-se nos portais centenários, gatos miavam nos telhados, violões gemiam serenatas. Era uma noite de encantamento, toques de atabaques ressoavam ao longe, o Pelourinho parecia um cenário fantasmagórico (AMADO, 2005, p. 82-83).

Desse modo, vê-se que o enredo criado por Jorge Amado permite descobrir novos sentidos ao texto literário e buscar as respostas necessárias para a possibilidade de compreensão do uso de mitos afro-brasileiros como inspiração da arte literária. A narrativa $A$ morte e a morte de Quincas Berro Dágua e a representação de seu protagonista permitiram entender que as relações interpessoais acontecem conforme as descrições dos arquétipos atribuídos aos filhos de Exu, com seu caráter dominador, intermediário e de líder da sua coletividade, além da exaltação e da adoração daqueles que o tem como amigo e parceiro.

\section{Referências}

AMADO, Jorge. A morte e a morte de Quincas Berro Dágua. Rio de Janeiro: Record, 2005.

A TARDE TV. Entrevista de Gildeci de Oliveira Leite. SEMINÁRIO CHAME GENTE, A Tarde TV, fev. 2012. Disponível em: < $\underline{\text { https://www.you- }}$ tube.com/watch?v=mbnkbUM0Ew0>. Acesso em 13 jul. 2018.

AUGRAS, Monique. O duplo e a metamorfose: a identidade mítica em comunidade nagô. 2. ed. Petrópolis, RJ: Vozes, 2008. (Coleção Identidade Brasileira)

BARCELLOS, Mário Cesar. Os orixás e a personalidade humana. 5. ed. Rio de Janeiro: Pallas, 2010.

BARCELLOS, Mário Cesar. Os orixás e a personalidade humana. 5. ed. Rio de Janeiro: Pallas, 2010.

CAPONE, Stefania. A busca da África no candomblé: tradição e poder no Brasil. Rio de Janeiro: Contra Capa: Pallas, 2009. 
LUCAS, Fábio. O caráter social da ficção no Brasil. São Paulo: Ática, 1985.

PRANDI, Reginaldo. Exu, de mensageiro a diabo: sincretismo católico e demonização do orixá Exu. In: Revista USP, São Paulo, n. 50, p. 46-63, junho/agosto 2001. Disponível em: <http://www.revistas.usp.br/revusp/article/view/35275>. Acesso em 13 jul. 2018.

Deuses africanos no Brasil: uma apresentação do candomblé. In: Herdeiras do axé. São Paulo: Hucitec, 1997. Disponível em: <http://www.fflch.usp.br/sociologia/prandi/her-axe1.htm>. Acesso em 13 jul. 2018.

. Mitologia dos orixás. São Paulo: Companhia das Letras, 2001.

. Axé, corpo e almas: concepção de saúde e doença no candomblé. In: BLOISE, Paulo (Org.). Saúde integral: a medicina do corpo, da mente e o papel da espiritualidade. São Paulo: Editora Senac, 2011. Disponível em: <http://www.fflch.usp.br/sociologia/prandi/axealma.doc > Acesso em 13 jul. 2018.

- Religião e sincretismo em Jorge Amado. In: GOLDSTEIN, Ilana Seltzer; SCHWARCZ, Lilia Moritz (Org.). O universo de Jorge Amado: orientações para o trabalho em sala de aula. São Paulo: Companhia de Letras, 2009. (Caderno de Leituras, Coleção Jorge Amado). 